\title{
IMPORTANCIA DE LOS MÉTODOS ALTERNATIVOS DE SOLUCIÓN DE CONTROVERSIAS EN EL SISTEMA PENAL ACUSATORIO MEXICANO
}

\author{
Importance of alternative methods of dispute resolution in the penal \\ system mexican accusatory
}

\author{
Christian Norberto Hernández Aguirre \\ Jessica Mendivil Torres \\ Cynthia Vedelí Hernández Aguirre
}

\begin{abstract}
Sumario:
I. Introducción, II. La implementación de los MASC en materia penal, III. Los MASC y su regulación conexa con la reforma penal, IV. Comentarios a la Ley Nacional de Mecanismos Alternativos de Solución de Controversias en Materia Penal, V. Propuesta de protocolo para los operadores de los MASC y su derivación, VI. Conclusiones, VII. Fuentes de consulta.
\end{abstract}

Resumen: En el presente artículo, se ofrecen algunas reflexiones respecto a los métodos alternativos de solución de controversias o MASC aplicables a la materia penal y la legislación relativa, desde una perspectiva doctrinal y crítica sobre las formas de intervención en la resolución de controversias, analizándose la reforma constitucional penal, Código Nacional de Procedimientos Penales y, principalmente, de la nueva Ley Nacional de Mecanismos Alternativos de Solución de Controversias en Materia Penal, con lo que se hace posible armonizar nacionalmente a los MASC en esta materia, así como, se propone un protocolo de actuación para los terceros ajenos al conflicto que podrían encauzar y derivar controversias, como lo puede ser, un mediador, conciliador, fiscal o juzgador, en pro de un sistema penal humanizador.

Palabras clave: métodos alternativos, conflictos penales, regulación, protocolo y justicia restaurativa.

Abstract: In this paper, some reflections on alternative methods of dispute resolution, or ADR applicable to criminal matters and legislation on offer, from a doctrinal and critical perspective on the forms of assistance in the resolution of disputes, analyzing the reform criminal constitutional, National Code of Criminal Procedure, and especially of the new National Law Alternative Dispute Resolution Mechanisms in Criminal Matters, which is made possible nationally harmonize ADR in this matter and a proposed protocol acting for third parties to the conflict that could lead channel and controversies, as it can be, a mediator, conciliator, prosecutor or judge, towards a humanizing penal system.

\footnotetext{
${ }^{1}$ Profesor de tiempo completo, de la Universidad Autónoma de Baja California, doctor en derecho, miembro del Sistema Nacional de Investigadores, nivel I, christian8879@uabc.edu.mx.

* Profesora de tiempo completo, de la Universidad Autónoma de Baja California y maestra en criminología, mendivilj@uabc.edu.mx.

${ }^{* *}$ Especialista y capacitadora en Mediación, adscrita al Centro Estatal de Justicia Alternativa del Poder Judicial del Estado de Colima, licenciada en derecho, vedeliz7@hotmail.com.
} 
Keywords: alternative methods, criminal disputes, regulation, protocol and restorative justice.

\section{INTRODUCCIÓN}

Cuando se suscita una controversia o conflicto en la sociedad que puede ser ocasionado por diversas fuentes y con diversas dimensiones, ${ }^{2}$ se puede o se busca resolver mediante varios recursos o medios, lo que puede hacerse con un trabajo interdisciplinario y multidisciplinar, es decir, de manera integral y transversalmente, lo que puede permitir una mejor calidad en la intervención ante la posible solución de una controversia, teniendo en consideración la particularidad de cada organismo y personas que intervienen como a las competencias que se requieren sobre las distintas temáticas a tratar; lo que ayudar a favorecer un mejor empleo o elección de los métodos o mecanismos para la solución de controversias jurídicas, ${ }^{3}$ lo cual, puede realizarse con o sin la intervención de terceros que pueda propiciar diversas soluciones, ${ }^{4}$ que se pueden desprender tanto de una terapia o tratamiento como de una investigación, litigio, arbitraje, negociación, conciliación o mediación (en un sentido enunciativo y no limitativo, nos referimos a algunas formas tanto herecompositivas como autocompositivas que se utilizan para la resolución de controversias jurídicas).

Por lo que en el presente análisis, se reflexiona sobre la mediación y conciliación, extendidos a fórmulas o expresiones que podrían contribuir a una justicia restaurativa o reparadora del daño, donde el castigo pueda ser sustituido por la aceptación de la responsabilidad de los hechos conflictivos y la búsqueda de métodos para su mejor solución. Lo que requiere de

\footnotetext{
${ }^{2}$ Un conflicto es primero y, principalmente, una ocasión de crecimiento en dos dimensiones críticas e interrelacionadas de la moral humana. La primera dimensión implica el fortalecimiento del yo. Se le obtiene mediante la compresión y el fortalecimiento de la capacidad humana intrínseca de cada uno para afrontar las dificultades de toda clase comprometiéndose en la reflexión, la decisión y la acción como actos conscientes e intencionales. La segunda dimensión implica superar los límites del yo para relacionarse con otros. Se le consigue comprendiendo y fortaleciendo la capacidad humana inherente del individuo para experimentar y expresar interés y consideración por otros, y especialmente por aquellos cuya situación es "distinta" de la que uno mismo tiene. BARUCH BUSH R. A. y FOLGER, J. P., La promesa de mediación. Cómo afrontar el conflicto a través del fortalecimiento propio y el reconocimiento de los otros, Argentina, Granica, 1994, pp.129-130.

Por otro lado, REDORTA, Josep, Como analizar los conflictos. La tipología de conflictos como herramienta de mediación, Buenos Aires, Paidós, 2004, p. 27 y ss. Con otra perspectiva a cerca de un conflicto y, de manera particular desde la psicología social aduce, que el conflicto se torna complejo, multidisciplinar y con una dispersión teórica en sus fuentes. El núcleo del conflicto está constituido por el poder y sus distintas formas, en la medida que el poder está presente de continuo en las relaciones sociales. El recurso al poder y a la influencia tiene por objetivos personales que están limitados por algo o por alguien. Sobre la tipología de los conflictos, elabora una estructura compuesta por fuentes y sus desencadenamientos, como son: metas, contexto, partes, poder, función, expectativas, ejes, vivencia, ciclo, normas, estilo, complejidad y ámbito. Para lo que podríamos llamar fuentes del conflicto que contribuyen a su complejidad, podemos aludir a HOBBES, Thomas, Leviatán: la forma y poder de un estado eclesiástico y civil, Alianza, Madrid, 2002, p. 115. Quien expresa que, en la naturaleza del hombre encontramos tres causas principales de disensión. La primera es la competencia. En segundo lugar, la desconfianza; y en tercer lugar, la gloria.

3 De aquí en adelante, a los mecanismos alternativos de solución de controversias los llamaremos MASC y, no se abreviarán cuando se cite a la legislación relativa.

${ }^{4}$ La forma de manejar el conflicto de una persona se ve influenciada por la medida en la que dicha persona intenta satisfacer sus propias inquietudes o preocupaciones y la medida en la que la misma intenta satisfacer las preocupaciones o inquietudes de la otra persona. Para mayor información, en cuanto a los estilos personales de resolución de conflictos véase "Proyecto para la Mediación en México", Manual del mediador, ABA/ USAID, 2004, p. 5 y ss.
} 
una participación tanto del ofensor como de la víctima y en su caso, de terceros. ${ }^{5} \mathrm{Al}$ observar la posibilidad de una negociación asistida y no impuesta que puede influir implícitamente en las partes y en la solución de controversias, se aduce que los MASC pudieran ser viables en materia penal, ${ }^{6}$ para un beneficio real y efectivo, con lo que a su vez, pueda auxiliarse no solo al descongestionamiento del sistema de administración de justicia, sino también, a una forma participativa y democrática, ${ }^{7}$ como a su mejor interpretación y funcionamiento en un mismo plano constitucional, junto con el apoyo de otros derechos fundamentales.

El Poder Judicial de la Federación en México $^{8}$ ha aducido en cuanto a los MASC y la oportunidad a su acceso que se debe garantizar para la solución alternativa de controversias jurídicas y al ser considerado un derecho humano (como por ejemplo, al relacionarse los MASC con el derecho a la tutela judicial); lo anterior, derivado de la diversa interpretación del segundo párrafo del artículo 17 de la Constitución Política de los Estados Unidos Mexicanos, así como, del $8^{\circ}$ de la Convención Americana sobre Derechos Humanos y 14 del Pacto Internacional de Derechos Civiles y Políticos; con lo que se pueda privilegiar la responsabilidad personal, el respeto y la utilización de la negociación, como forma de comunicación asistida y alternativa para un desarrollo colectivo y sinérgico.

Por otro lado, la relación de la mediación y conciliación con la justicia restaurativa, se hace propicia y respaldada porque mediante ellos se puede abrir la posibilidad de que intervengan infractor y víctima $\mathrm{o}$, ante la falta de una forma voluntaria se asista por un tercero neutral e imparcial, que en su conjunto podrán tratar de alcanzar, a través, de la comunicación y el diálogo, un espacio de encuentro flexible, confidencial y equitativo, con miras a una reparación del daño del injusto causado, evitando la posible polarización que se da ante una resolución judicial.

5 PÉREZ SAUCEDA, José Benito y ZARAgOZA HUerTA, José, en Campos Domínguez, Fernando G., Cienfuegos Salgado, David, Rodríguez Lozano, Luis G., Zaragoza Huerta, José (coords.), “Justicia Restaurativa: del castigo a la reparación", Entre libertad y castigo: dilemas del estado contemporáneo. Estudios en homenaje a la maestra Emma Mendoza Bremauntz, Editora Laguna, México, 2011, p. 640.

${ }^{6}$ Ciertamente, en el mundo del Derecho, una solución conciliadora no siempre será viable, en ocasiones incluso por dificultades procesales, pero representa con toda probabilidad el camino más adecuado...que puede desembocar en una indemnización o en otras medidas susceptibles de graduación...para mayor información véase PRIETO SANCHÍS, Luis, "El juicio de ponderación constitucional", en El principio de proporcionalidad y la interpretación constitucional, V\&M Gráficas, Ecuador, 2008, p. 103.

7 En jurisprudencia constitucional, la Corte Constitucional de Colombia, también ha reconocido el carácter democrático y participativo de los MASC, al aducir que: “... no deben ser interpretados solamente como una manera de descongestionar el aparato de justicia sino también, y principalmente, como una forma de participación de la sociedad civil en los asuntos que los afectan. En este sentido, es incuestionable su estirpe democrática, en la medida en que generan espacios de intervención de la comunidad en el desarrollo de la función jurisdiccional evitando la conflictivización de la sociedad y logrando, por ende, el fortalecimiento de la legitimidad del aparato de justicia estatal...Desde esta perspectiva, se ha considerado que el presupuesto básico para la efectividad de la justicia consensual es la existencia de una sociedad civil organizada, integrada cultural, valorativa y normativamente..."

Sentencia C-893/o1, http://www.corteconstitucional.gov.co/relatoria/2001/C-893-01.htm\#_ftn12. 12 de Mayo de 2014 .

8 Tesis: III.20.C.6 K (10a.), Semanario Judicial de la Federación y su Gaceta, Décima Época, Tomo 3, octubre de 2013, p. 1723 y Tesis: PC.III.P. J/1 P (10a.), Semanario Judicial de la Federación y su Gaceta, Décima Época, Tomo II, mayo de 2014, p. 133. 


\section{LA IMPLEMENTACIÓN DE LOS MASC EN MATERIA PENAL}

El empleo de los MASC se plantea para hacer efectivo el derecho a una justicia rápida y al alcance de todos; siendo que, al tener el derecho a una justicia alternativa se implica una gama de resultados o acciones posibles, al centrarse en áreas de oportunidad, acuerdos o temas comunes (como puede suceder, en una negociación, como más aún, en una negociación asistida), lo anterior, sin los costos de tiempo, esfuerzo, desgaste de recursos humanos y materiales, como suele suceder en un proceso judicial, esto, en beneficio de la persona, en la búsqueda del diálogo, respeto y reconocimiento de una verdad aproximativa o redefinición de una controversia.

Por otro lado, en nuestro país, se ha venido dando paulatinamente el conocimiento y práctica de la mediación, ${ }^{9}$ por mencionar uno de los MASC que sigue en expansión, con lo que se sigue dando frente al miedo sobre el cambio de paradigma en la forma de resolución de controversias jurídicas y, a la concientización de abogados acostumbrados a dirimir controversias por medio del litigio ante un tercero que decida y ejecute; a la par, se hace necesaria la evolución de la política criminal como de la teoría de la pena, con lo que se contribuya a más formas de solución y hasta a la reducción de penas, respectivamente, con lo que se pretenda, no solo bajar el número de expedientes e incidir en el tiempo de su resolución (que ya sería un buen inicio en caso de ser así), sino también, en la búsqueda de materializar soluciones de manera efectiva (como por ejemplo, al celebrarse acuerdos reparatorios o una suspensión condicional del proceso) o formas anticipadas de terminar un proceso (como por ejemplo, al ser propicio un procedimiento abreviado, antes de un juicio oral y sin todos los principios procesales y constitucionales que conllevan a éste, respecto al sistema acusatorio en México; tema que ahora no atenderemos).

Por lo que con la implementación debida de los MASC en materia penal, se aduce que se busca crear un espacio donde se tomen en cuenta las necesidades y tranquilidad de la víctima, victimario, sociedad y Estado, que alrededor de ellas se pueden situar (por mencionar un ejemplo, los familiares de las partes en controversia) y, que algunas formas para llegar a su efectividad implica hacer una revalorización del conflicto, propiciando empatía, licitud del posible acuerdo, entre otros aspectos sustanciales, con lo que se pueda favorecer una política criminal preventiva, integradora y menos represiva, que auxilie a un control y reinserción social, con lo que se siga preservando el efecto preventivo del Derecho Penal, que se aduce con la imposición de una pena o medida de seguridad; para que sea vista a la mediación o conciliación como fórmulas de expresión que encausen, posiblemente, dependiendo el caso

\footnotetext{
9 La incorporación de una Ley sobre Medios Alternos de Solución de Conflictos en México data de 1997, año en el que fue creada la primera legislación local en nuestro país, en el estado de Quintana Roo. La extensión de las legislaciones locales sobre justicia alternativa al resto del país, se ha dado paulatinamente. Aunque para el año 2000 únicamente, Quintana Roo y Querétaro ofrecían dichos servicios, algunas entidades federativas, estaban a punto de abrir sus respectivos Centros de Justicia Alternativa (como en el caso de Baja California Sur, que lo hizo en enero de 2001) y muchas otras realizaban labores de investigación para hacerlo en el corto plazo. Aunque si bien, dentro de la justicia alternativa se encuentra la conciliación, la cual se práctica y es regulada desde hace muchos años, esta, tradicionalmente se encuentra dentro de un juicio, por lo que se ha convertido en una instancia más de un proceso judicial. Es cierto que ha dado resultados, pero no se ha abatido un porcentaje considerable de asuntos por esta vía. Para mayor información sobre la incorporación de los medios alternativos en México, entre otros temas sobre mediación penal, véase MÁRQUEZ ALGARA, María Guadalupe y DE VILLA CORTÉS, José Carlos, “La justicia restaurativa y la mediación penal en México”, revista De Jure, Universidad de Colima, México, año 3, No. 8, Mayo 2011, pp. 111 y ss.
} 
en concreto y posible delito, la mejor concreción de una reparación del daño, como también a una Justicia Restaurativa.

La Justicia Restaurativa, de manera general, consiste en un proceso, por el cual, las partes que tienen interés en un determinado conflicto, se juntan para resolverlo colectivamente y para tratar sus implicaciones de futuro. ${ }^{10}$ Es una forma de responder al comportamiento delictivo balanceando las necesidades de la comunidad, de las víctimas, victimarios y del Estado. Algunas características de la Justicia restaurativa son: el constituirse en una respuesta flexible a las circunstancias de un delito, delincuente y víctima, que permita que cada caso sea considerado individualmente; ser una respuesta al crimen, que respete la dignidad y la igualdad, que se desarrolle el entendimiento y promueva la armonía social, a través, de la reparación del daño a las víctimas y comunidades; una alternativa viable al sistema de justicia penal formal y a sus efectos estigmáticos sobre los delincuentes; un método que puede usarse en conjunto con los procesos y las sanciones de la justicia penal tradicional; un método que incorpora la solución de los problemas y está dirigido a las causas subyacentes del conflicto; una metodología que motiva al delincuente a comprender las causas y efectos de su comportamiento y a asumir su responsabilidad de una manera significativa; una metodología flexible y variable que puede adaptarse a las circunstancias, la tradición legal, los principios y filosofías de los sistemas nacionales de justicia penal. ${ }^{11}$

Por lo que se aduce, que en un proceso restaurativo puede acontecer una formula autocompositiva, ${ }^{12}$ con lo que se puede propiciar un mejor control social de las consecuen-

${ }^{10}$ GORDILLO SANTANA, Luis, "Los principios constitucionales y las garantías penales en el marco del proceso de mediación penal" en Revista Redur, No. 4, Universidad de La Rioja, Departamento de Derecho, 2006, p. 2.

${ }^{11}$ Manual sobre programas de Justicia restaurativa, Oficina de las Naciones Unidas contra la droga y el delito, Nueva York, 2006. http://www.unodc.org/documents/justice-and-prisonreform/Manual_sobre_Programas_de_justicia_restaurativa.pdf. Fecha de consulta 05 de marzo de 2013.

${ }^{12}$ Se puede definir a la autocomposición, como un supuesto en el que son las partes las que arreglan entre sí sus diferencias y, si interviene un tercero, éste no tiene capacidad decisoria sino capacidad de influencia limitada. A diferencia de la heterocomposición, en que la idea central reside en que un tercero toma una decisión respecto a cómo resolver el conflicto: un juez, un árbitro, el rey, el jefe de la tribu etc. Supuesto en el que se presume que el tercero tiene capacidad de decisión y de ejecutar lo decidido.

Por lo que la fórmula autocompositiva, adquiere importancia al ser las partes (en materia penal, víctima y acusado) quienes resuelven su conflicto o controversia, con base en sus petitum, en algunos casos haciéndose múltiples concesiones, donde pudiera haber o no la intervención de un tercero que induzca a la solución. REDORTA, Josep, op. cit., nota 2, p. 38. En el mismo sentido, aduce, GORJÓN GÓMEZ, Francisco Javier "Medios alternativos de solución de controversias. Solución a la impetración de la justicia", en ELIALA, año 2, núm. 3. UANL, México, 2002. Que los MASC actúan y operan sólo si existe la voluntad de la partes para que eso ocurra. De no ser así, no se pueden considerar funcionales, ya que su principal característica es el espíritu de autocomposición de las partes.

Por lo que no pudimos estar de acuerdo con OVALLE FAVELA, José en Teoría General del Proceso, $10^{\mathrm{a}}$ ed., Oxford, México, 2011, pp.23-33, al incluir a la Mediación y Conciliación junto con el Arbitraje y el Proceso judicial, entre las formas de solución heterocompositivas (sin hacer distinción), donde parece, que se confunde la influencia que puede tener un tercero con la voluntariedad de las partes en la decisión y la propuesta que puede dar un conciliador para la solución de un conflicto, siendo, que la decisión y ejecución en el caso de un arbitraje y proceso judicial, está en "manos" de un árbitro o un juzgador, respectivamente, donde las partes, si bien, pueden someterse voluntariamente fuera de un proceso judicial, como en el caso del arbitraje, (que si bien el arbitraje sigue siendo uno de los MASC, este es heterocompositivo, como el autor lo define) en el que se puede dictar un laudo o someterse las partes al mismo, por medio de una cláusula arbitral, siendo que, la decisión y ejecución del laudo, sigue estando en manos de un árbitro; o del juez, en el caso de un proceso judicial, a diferencia en la mediación (por mencionar uno de los MASC autocompositivos) se busca que las 
cias jurídicas de un delito, ${ }^{13}$ lo que no sólo se hace posible mediante una fórmula heterocompositiva (que puede acontecer por ejemplo, en un juicio); y se siga haciendo propicio, atender a un delito o posible delito con un enfoque generativo y transformador, a través, de una revalorización y reconocimiento; con lo que se pueda llegar hasta la limitación o reducción de una pena, reto que va más allá de una política criminal basada en la expansión de conductas consideradas delictivas sin el análisis y comprensión de su mejor solución y bien jurídico a tutelar, lo que puede provocar un efecto penal "simbólico". ${ }^{4}$

En concordancia con Baratta, el reto que se debe plantear hoy al derecho penal y procesal penal en un estado social y democrático, es el de ser coherente con sus principios garantistas y de derechos humanos. En este sentido, un uso alternativo del derecho penal significa, ante todo, aplicarlo, transformarlo y reducirlo. Significa poner una técnica rigurosa de limitación, de lo que tal vez, en un tiempo parecía una función útil y que hoy, cada vez más, aparece como la violencia inútil de las penas. Esto presupone, un uso instrumental del Derecho penal liberado de la ilusión de la instrumentalidad de la pena. ${ }^{15}$

\section{LOS MASC Y SU REGULACIÓN CONEXA CON LA REFORMA PENAL}

Los MASC en México con la reforma constitucional penal de 18 de junio de 2008, entre otras, siguen progresando ${ }^{16}$ así mismo, con la expedición de un Código Nacional de Procedimientos Penales ${ }^{17}$ y la publicación de la nueva Ley Nacional de Mecanismos Alternativos de Solución de Controversias en Materia Penal, lo puede seguir haciendo posible ${ }^{18}$ con la

partes solucionen su conflicto voluntariamente, como sucede con el convenio o acuerdo producido, lo anterior, sin la decisión o ejecución "en manos" de un tercero.

${ }^{13}$ Sobre un control social y MASC en materia penal, véase sustancialmente BARATTA, Alessandro, Criminología y Sistema Penal, B de F, Buenos Aires, 2004, p. 152. En donde aduce que para el control de las consecuencias del delito, las actuales teorías prevén, sobre todo, el uso de instrumentos no penales, en particular conciliatorios (la mediación en sus diversas formas), y restitutivos. Solamente en el ámbito de las teorías de las funciones simbólicas de la pena (teoría clásica y contemporánea de la retribución, teoría actual de la prevención general positiva o prevención-integración, y otras teorías), el instrumento principal para el control de las consecuencias del delito es la pena.

14 El Derecho penal simbólico, se da bajo formas muy diversas: derecho penal que está menos orientado a la protección del bien jurídico que a efectos políticos más amplios como la satisfacción de una "necesidad de acción”. Es un fenómeno de la crisis de la política criminal actual orientada a las consecuencias. Ello convierte gradualmente al Derecho penal en un instrumento político flanqueador de bienes jurídicos universales y delitos de peligro abstracto. Este Derecho penal se aviene a las imágenes de una "inseguridad global” y de una "sociedad de riesgo". Un Derecho penal simbólico con una función de engaño no cumple la tarea de una política criminal y mina la confianza de la población en la Administración de Justicia. Para mayor información sobre derecho penal simbólico, véase HASSEMER, Winfried, Porque no debe suprimirse el Derecho Penal, INACIPE, México, D. F., 2003, p. 62.

15 BARATTA, Alessandro, Op. Cit., nota 13, p. 88.

${ }^{16}$ Con la necesidad también de establecer un sistema de mecanismos alternativos al juicio, que permitan por una parte, brindar una justicia más rápida y efectiva tanto a la víctima como al imputado $\mathrm{y}$, otra, descongestionar el sistema de casos menores para enfocar la atención a aquéllos que efectivamente deben llegar a juicio. Para más información véase Suprema Corte de Justicia de la Nación, El sistema penal acusatorio en México: estudios sobre su implementación en el poder judicial de la federación, México, Dirección General de la Coordinación de Compilación y Sistematización de Tesis, 2008, p. 44 y el artículo 17 constitucional devenido de la reforma constitucional penal de 2008.

17 Publicado en el Diario Oficial de la Federación, el o3 de marzo de 2014.

${ }^{18}$ El 29 de diciembre de 2014, se publicó en México en el Diario Oficial de la Federación la Ley Nacional de Mecanismos Alternativos de Solución de Controversias en Materia Penal que entrará en vigor en los mismos términos y plazos en que entrará en vigor el Código Nacional de Procedimientos Penales (18/o6/2016) http:// 
finalidad de seguir contribuyendo a soluciones alternativas de controversias en materia penal, abatimiento del retraso de expedientes y el incumplimiento de términos procesales, entre otras demandas de la sociedad, que pueden afectar no sólo formalmente a las partes $y$, con lo que se denota la preocupación ante la violencia y formas de solución, así como, con la inclusión de varias teorías y métodos en la complejidad de un conflicto, donde no solo se precisa la voluntad e intervención del Estado.

Por otro lado, en algunas entidades federativas, las etapas o fases de los MASC en materia penal, entre otros aspectos, sigue estando esencialmente bajo la supervisión del Tribunal Superior de Justicia o bajo la conducción o derivación de la Procuraduría General de Justicia (además, de los Centros Estatales de Justicia Alternativa (CEJA), que en la mayor parte del país existen, separados o especializados a la materia penal, como en Baja California que cuenta con un CEJA y un SEJAP o Sistema Estatal de Justicia Alternativa Penal o, algunos estados que incluyen a los MASC en materia penal en su legislación relativa junto con otras materias, como por ejemplo, en Sonora o Colima, por decir alguno).

Por lo que en concordancia con Zaragoza Huerta, la reforma penal en México, hace gala de otra de sus innovaciones, la justicia alternativa. ¿Qué implica la misma? La justicia alternativa responde a criterios de utilitarismo y eficacia jurídica. Finalmente, a la víctima u ofendido de "determinados delitos" le interesa más ser resarcido en su menoscabo personal y evitar "tortuosos" procedimientos que propician la intervención de algunos de los actores del proceso penal que lo alargan y entorpecen. ${ }^{19}$ En materia penal, las salidas alternas de justicia están relacionadas con mecanismos en donde se presupone que dotarán de rapidez, eficacia y un equilibrado interactuar. Este tipo de estrategias puede generar un conjunto de falsas expectativas ante los MASC, en cuanto a las mejoras que podrían devenir en México ante la violencia estructural y su abatimiento, por lo que se hace necesario, su conocimiento, difusión, proyección, regulación y cambios jurídicos sustanciales apegados a criterios como valoraciones de derechos humanos, para su mejor comprensión en cuanto a la generación de formas de solución que no incide necesariamente en la reducción de la violencia.

Se comparte lo aducido por Fried, al expresar que los conflictos entre personas, sistemas o subsistemas de sistemas complejos, pueden percibirse como un aspecto indeseable o como una oportunidad de cambio. Las metodologías para resolución alternativa de controversias facilitan la definición y administración responsable - por individuos, organizaciones y comunidades - de los propios conflictos y de la vía hacia soluciones. La mediación ${ }^{20}{ }^{20}$ como el

www.dof.gob.mx/nota_detalle.php?codigo=5377563\&fecha=29/12/2014. Fecha de consulta: o6 de enero de 2015.

19 ZARAGOZA HUERTA, José "Los mecanismos de solución de conflictos penales: un recuento de su implementación en Panamá y México”, en PRADO MAILLARD, José Luis y GORJÓN GÓMEZ, Francisco Javier (coord.), Modernización de la justicia desde la perspectiva panameña y mexicana, Panamá, Carpal, 2013, pp.105-106.

${ }^{20}$ Que se puede definir como un procedimiento no adversarial (en el sentido de que no se enfrentan ni se definen los conflictos como se hace en un proceso judicial), pacífico y cooperativo de solución de conflictos. Su objetivo es impulsar un acercamiento entre las personas envueltas en una disputa, ayudarlas a clarificar e identificar los intereses, para que desemboquen en un acuerdo satisfactorio (...) cfr. MÁRQUEZ ALGARA, Ma. Guadalupe, "Desarrollo de la mediación judicial en México”, Jurisconsulto, Aguascalientes, año 1, número 1, México, Julio-Diciembre de 2005, p.9. Lo puesto entre paréntesis es mío.

En el mismo sentido en Cuadernos del Mercosur, número 12, p. 3. Se aduce que en la mediación no se producen ganadores ni perdedores, ya que todas las partes deben ser favorecidas con el acuerdo que se logre. Para mayor información véase "La mediación en Argentina y el Mercosur." 
empleo de diversas metodologías, pueden facilitar el diálogo, proveer vías y proponer destrezas para la solución de situaciones conflictivas. ${ }^{21}$

Por otro lado, la poca credibilidad y confianza de la sociedad en la Administración de Justicia ha generado, que los sistemas judiciales cuenten con poca valoración y aceptación, al punto de expresarse una crisis en cuanto a su accesibilidad, funcionamiento y beneficios; ${ }^{22}$ que pareciera derivar de deficiencias estructurales del derecho liberal para enfrentar la conflictividad en la modernas sociedades de masas, en que se ha obtenido como resultado, la falta de eficacia en la lucha contra el crimen, el rezago judicial y procesos lentos con usuarios descontentos, como síntomas comunes del problema, ${ }^{23}$ lo que puede explicar ciertas orientaciones y oportunidades para emplear los MASC.

\section{COMENTARIOS A LA LEY NACIONAL DE MECANISMOS ALTERNATIVOS DE SOLUCIÓN DE CONTROVERSIAS EN MATERIA PENAL}

En México, con la reforma constitucional federal del artículo 17 , en su tercer párrafo, ${ }^{24}$ y que su esencia radica en fortalecer y seguir con la búsqueda de métodos que contribuyan a más formas de solución ante un posible caso penal, teniendo como vías el perdón y la operacionalización entre víctima y victimario, a través, de un mecanismo que facilite un acuerdo; y con la modificación de la fracción XXI, inciso c) del artículo 73 constitucional, ${ }^{25}$ se sigue haciendo posible la oportunidad de acudir a los MASC a nivel nacional en materia penal, como ya se ha hecho antes de dichas reformas en la mayoría de las entidades federativas (como por ejemplo, en Baja California, Nuevo León, Guanajuato, Sonora, Querétaro y Yucatán, por mencionar algunas) y con lo que se siguen adaptando con la nueva Ley Na-

\footnotetext{
${ }^{21}$ SCHNITMAN DORA, Fried (Comp.), Nuevos paradigmas en la resolución de conflictos. Perspectivas y prácticas, Granica, Buenos Aires, 2000, pp. 17-18.

${ }^{22}$ Sobre posibles causas por las que se aduce que se ha originado una crisis en el sistema judicial véase, GORJÓN GÓMEZ, Francisco Javier y STEELE GARZA, José G., Métodos alternativos de solución de conflictos, $2^{\mathrm{a}}$ ed., Oxford. México, 2012, pp. 7-8. En donde mencionan cinco causas, que en forma resumida se mencionan, las siguientes: 1. El Poder Judicial no se da abasto para cumplir con la demanda de resolución de litigios que le exige la sociedad...2...El difícil acceso a la justicia, 3. La ignorancia y el escaso conocimiento de los MASC por parte de la sociedad...4. . Los abogados...pensando sólo en el beneficio económico, con lo que se deja a un lado el beneficio real de la sociedad, y 5. Los demás profesionales en otras áreas del conocimiento que-creen que, por no ser especialistas en leyes, eso les impide resolver por ellos mismos sus problemas.

${ }^{23}$ FIERRO FERRÁEZ, Ana Elena, Manejo de conflictos y mediación, Ed. Oxford, México, 2010, p. 16.

${ }^{24}$ De 29 de julio de 2010, precepto en el que se dispone: "las leyes preverán mecanismos alternativos de solución de controversias. En la materia penal regularán su aplicación, asegurarán la reparación del daño y establecerán los casos en los que se requerirá supervisión judicial.”

${ }^{25}$ En el que se señala, como facultades del Congreso de la Unión, para legislar sobre: la legislación única en materia procedimental penal, de mecanismos alternativos de solución de controversias y de ejecución de penas que regirá en la República en el orden federal y en el fuero común.

En el artículo segundo transitorio que se generó con esa propuesta de reforma, se dispone que: "la legislación única en las materias procedimental penal, de mecanismos alternativos de solución de controversias y de ejecución de penas que expida el Congreso de la Unión conforme al presente Decreto, entrará en vigor en toda la República a más tardar el día dieciocho de junio de dos mil dieciséis.” Dentro del mismo transitorio, se señala que: "la legislación vigente en las materias procedimental penal, de mecanismos alternativos de solución de controversias y de ejecución de penas expedida por el Congreso de la Unión, las legislaturas de los Estados y la Asamblea Legislativa del Distrito Federal continuará en vigor hasta que inicie la vigencia de la legislación que respecto de cada una de dichas materias expida el Congreso de la Unión conforme al presente Decreto."
} 
cional de Mecanismos Alternativos en Materia Penal, en particular, sobre la mediación ${ }^{26}$ y conciliación ${ }^{27}$ con lo se hace posible seguir con un proceso restaurativo más centrado en la reparación y reconocimiento que en la punición y con lo se podrían seguir produciendo mas formas de llegar a una reinserción y control social para responder a necesidades de las víctimas y, a la disposición voluntaria del acusado, como al reconocimiento de su dignidad. Así mismo, con el CNPP, se sigue dando cabida a acuerdos reparatorios, ${ }^{28}$ como ya se ha empezado a hacer en diversos códigos procesales penales de las entidades federativas con la implementación del sistema acusatorio, lo que puede llevar hasta la suspensión de un procedimiento o proceso, y con lo que se puede contribuir a un resultado restaurador.

Por justicia restaurativa se entiende, en un sentido amplio, la filosofía y el método de resolver los conflictos que atienden prioritariamente a la protección de la víctima y al restablecimiento de la paz social, mediante el diálogo comunitario y el encuentro personal entre los directamente afectados, con el objeto de satisfacer de modo efectivo las necesidades puestas de manifiesto por los mismos, devolviéndoles una parte significativa de la disponibilidad sobre el proceso y sus eventuales soluciones, procurando la responsabilización del infractor y la reparación de las heridas personales y sociales provocadas por el delito. Dependiendo del marco legal y de las peculiaridades sociales y culturales, adoptará unas u otras modulaciones. ${ }^{29}$

En el mismo sentido, por justicia restaurativa se concibe, a un proceso donde la partes con riesgo en un delito específico, resuelven colectivamente el cómo tratar, las consecuencias de un delito y sus implicaciones en un futuro. ${ }^{30}$ Cediendo la justicia retributiva a la alternativa,

${ }^{26}$ Ley Nacional de MASC en donde se define a la mediación en su artículo 21, como “...el mecanismo voluntario mediante el cual los Intervinientes, en libre ejercicio de su autonomía, buscan, construyen y proponen opciones de solución a la controversia, con el fin de alcanzar la solución de ésta. El Facilitador durante la mediación propicia la comunicación y el entendimiento mutuo entre los Intervinientes."

Así mismo, Fernado Moya, Manuel, citado en Técnicas del Proceso Oral en el Sistema Penal Acusatorio Colombiano. Manual General para Operadores Jurídicos, $2^{\mathrm{a}}$ ed., Colombia, p. 48. Sobre la mediación penal, aduce, que es otro mecanismo de justicia restaurativa que ha sido considerada como un proceso de aproximación de las víctimas con sus victimarios, facilitado por un mediador, en un escenario de confrontación pacífica de la situación que actualmente viven y que ha surgido del delito.

${ }^{27}$ Ley nacional de MASC en materia penal, en donde se conceptualiza a la conciliación en su artículo 25, como: “...el mecanismo voluntario mediante el cual los Intervinientes, en libre ejercicio de su autonomía, proponen opciones de solución a la controversia en que se encuentran involucrados. Además de propiciar la comunicación entre los Intervinientes, el Facilitador podrá, sobre la base de criterios objetivos, presentar alternativas de solución diversas."

Por otro lado, en Técnicas del Proceso Oral en el Sistema Penal Acusatorio Colombiano. Manual General para Operadores Jurídicos, $2^{a}$ ed., Colombia, p. 48. Se expresa que, la conciliación, puede ser considerada una salida alterna al juicio oral, siempre y cuando sea aquella denominada preprocesal, porque la efectuada en el incidente de reparación integral referida a la pretensión resarcitoria es consecuencia de la realización de un juicio oral donde se ha hallado penalmente responsable al acusado. El objeto general de la conciliación preprocesal es lograr acuerdos reparatorios entre víctima y victimario. Lo anterior citado, se aduce formalmente porque sustancialmente pudiera considerarse su oportunidad dentro del mismo.

${ }^{28}$ En el CNPP se definen los acuerdos reparatorios, dentro del Artículo 186, como: "aquéllos celebrados entre la víctima u ofendido y el inculpado que, una vez aprobados por el Ministerio Público o el Juez de control y cumplidos en sus términos, tienen como efecto la conclusión del proceso penal."

${ }^{29}$ RÍOS MARTÍN, Julián Carlos et al, Justicia restaurativa y mediación penal. Análisis de una experiencia (2005-2008), Consejo General del Poder Judicial, 2008, Madrid, p. 14. en www.poderjudicial.es. Fecha de consulta 20 de junio de 2014.

${ }^{30}$ DOMINGO DE LA FUENTE, Virginia, "Justicia Restaurativa y Mediación Penal de la teoría a la práctica." Revista de derecho penal, Lex Nova, No. 23, Madrid, 2008, pp. 33-68. 
con lo que la víctima u ofendido y el victimario, se encuentren en la posibilidad de participar voluntaria y conjuntamente de forma activa en la resolución de cuestiones derivadas de un posible delito, en busca de un resultado restaurador o reparador, teniendo como algunos de sus límites razonables o de posible realización, la falta de identificación de un victimario o la falta de la participación voluntaria tanto de víctima como de victimario.

Por otro lado, con la nueva Ley Nacional de MASC de solución de controversias en Materia Penal en México, ${ }^{31}$ se trae una muestra del esfuerzo por armonizar y unificar su marco jurídico $;^{32}$ donde se hacen patentes principios rectores de los MASC, como la voluntariedad, información, confidencialidad, flexibilidad, simplicidad, imparcialidad, equidad y honestidad. Por lo que se precisa, se sigan creando instrumentos que contribuyan a clarificar y fortalecer las destrezas, habilidades, competencias generales y específicas que se hacen necesarias para los prestadores de servicios de los MASC a la sociedad para su mejor desempeño y función sistemática.

Por otro lado, la justica alternativa pudiera ser factible en diversas fases, una pre procesal (como puede ser, antes de comenzar una denuncia o querella a lo que deviene una etapa de investigación, en la que pudiera también proponerse o derivarse de la misma), intra procesal (después de trabada la litis ante el juez, como excepción propuesta en el juicio por la parte interesada, como una vez impuesta la pena o medida de seguridad por el Estado, lo que puede afectar a la ejecución de lo juzgado en favor de las partes y sociedad), otra extra procesal (como puede ser, con convenios o acuerdos celebrados ante un Centro de Justicia Alternativa de cada entidad federativa) y, otra endo o post procesal (que pudiera suceder, una vez que se esta ejecutando la sentencia) con lo que se puede hacer posible la armonización de intereses, principios y valores en diversos momentos.

En México, con esta nueva ley nacional de MASC en materia penal, se podría limitar o sobre limitar la llamada justicia alternativa a la primera fase hasta que exista denuncia o querella, y hasta la tercer fase en cuanto a momentos posibles, como sucede en algunas entidades federativas (como por ejemplo, en Baja California, con relación a su código ${ }^{33}$ en coherencia

${ }^{31}$ Dicha ley nacional, según su artículo primero transitorio, dispone que entraría en vigor en México, hasta que se implemente el nuevo Código Nacional de Procedimientos Penales en las entidades federativas, es decir, en los mismos términos y plazos, que según el mismo código establece dentro de su artículo segundo transitorio, donde se señala, que no podrá exceder al 18 de junio de 2016, además, de que algunas entidades federativas, como Sonora, Sinaloa, Durango, Morelos o Puebla, entre otras, que ya tienen implementadas diversas leyes estatales de justicia alternativa en materia penal, se verían sustituidas en el plazo y término que marca la vacación legal prevista en la Ley Fundamental (18/o6/2016), coincidente con los artículos transitorios del Código Nacional Adjetivo Penal y Ley Nacional de MASC en Materia Penal; por otro lado, las entidades federativas que no tengan implementada una Ley de Justicia Alternativa estatal en materia Penal, también se verían obligadas a implementar la ley de MASC, con las implicaciones de tiempo, recursos humanos y materiales que trae consigo.

32 Al poder desprenderse ciertas consecuencias que se persiguen, como lo son: a) aplicación de mecanismos que permitan matizar el carácter punitivo, del derecho penal en los casos no graves, en que pueden solucionarse los conflictos sin necesidad de llegar a un juicio e imponer una pena de prisión; b) privilegiar la reparación del daño, así como la restauración del tejido social; c) promover la transición del sistema de justicia penal; d) despresurizar las causas penales en el sistema mixto-inquisitivo para lograr su adecuada desactivación y e) establecer las bases para una exitosa instrumentación del sistema de justicia penal acusatorio.

${ }^{33}$ Como se observa, en su Código de Procesal Penal, que se venía implementando en sus municipios (siendo que, en Baja California existen dos códigos adjetivos penales mientras se implementa gradualmente el sistema acusatorio) con relación a la ley de MASC y su oportunidad en materia penal estatal; que inicialmente el código procesal penal se aplica en Mexicali y sucesivamente se ha detenido su implementación en los demás municipios, aunque la ley relativa a los MASC en materia penal, sigue su curso en los demás municipios, 
con su ley relativa, o en Durango, ${ }^{34}$ por mencionar algunas entidades) donde se coincide con el CNPP, siendo que, en otras entidades de la república mexicana ya se permite acudir a los MASC después de dictadas sentencias y una vez ejecutoriadas estas (inclusive, antes de publicado el CNPP, como por ejemplo, en Sonora, ${ }^{35}$ Querétaro ${ }^{36} \mathrm{y}$, Yucatán, ${ }^{37}$ por mencionar algunos estados) donde el empleo de los MASC en materia penal se hace susceptible en la cuarta fase (endo o post-procesal) para una reparación del daño, aunque no necesariamente se pudiera llevar a cabo una reparación del daño o restitución total en todos los casos y para todos los delitos. Así mismo, se hace la precisión sobre esta ley nacional, que ya no se podría acudir a los MASC antes de la presentación de una Querella (como sí se puede, por decir un ejemplo, actualmente en Guanajuato, ${ }^{38}$ entre otros), lo que pudiera parecer un retroceso en la búsqueda del diálogo, métodos y soluciones viables ante controversias jurídicas. ${ }^{39}$

Así mismo, sobre la solicitud para la aplicación de MASC, en la fracción X del artículo $3^{\circ}$ y $9^{\circ}$ con relación al $10^{\circ}, 11$ y 35 , respectivamente, de la citada Ley Nacional de MASC en Materia Penal, se observa que tanto el Ministerio Público como el Juez, local o de la federación, podrán ser autoridades competentes para la solicitud de su inicio, encause, derivación y cumplimiento de un acuerdo, con lo que se puede hacer posible orientar a las partes desde el inicio de un planteamiento penal, siempre y cuando haya denuncia o querella; es decir, el MP o Juez podrán estar en posibilidad de explicar a las partes sobre en qué consisten los MASC y sus ventajas, siempre y cuando se cumplan con los requisitos de procedencia y oportunidad que se deberán dominar para su transmisión de la mejor manera; ${ }^{40}$ en este

como por ejemplo, en Ensenada. CPPBC. Artículo 197.- Oportunidad.- La celebración de los acuerdos reparatorios procederá hasta antes de decretarse el auto de apertura de juicio oral.

${ }^{34}$ Ley de Justicia Penal Restaurativa del Estado de Durango. "artículo 4.- En los asuntos de materia penal que sean competencia de la Fiscalía General del Estado de Durango, los mecanismos alternativos de solución de conflictos o controversias, estarán a cargo de la Dirección, a través del personal especializado adscrito a las mismas y por conducto de Sub Direcciones Regionales.

Dichos mecanismos alternativos de solución de conflictos o controversias, se referirán a conductas que puedan constituir un delito, en los términos y condiciones que se establecen en el Código Nacional de Procedimientos Penales."

${ }^{35}$ Como se observa, en la Ley de Mecanismos Alternativos de Solución de Controversias para el Estado de Sonora, en su "Artículo 9...En materia penal, habiéndose dictado sentencia firme, sólo podrán tratar lo conducente a la reparación del daño."

${ }^{36}$ Como se puede observar en Ley de Justicia Penal Alternativa del Estado de Querétaro, que se sigue aplicando gradualmente en sus Municipios; dentro del Artículo $2^{\circ}$ de dicha ley que dispone: “... pudiendo acceder a ellos en cualquier etapa del procedimiento, incluso después de que la sentencia dictada haya causado ejecutoria, pero en este caso, sólo se podrá tratar lo conducente a la reparación del daño."

${ }^{37}$ Ley de MASC del estado de Yucatán, donde se dispone en su artículo 12 que "En materia penal, habiéndose dictado sentencia firme, sólo se podrá tratar lo conducente a la reparación del daño y el Ejecutivo proveerá lo necesario para facilitar el encuentro de la víctima con el victimario a fin de hacer efectiva la justicia restaurativa.

${ }^{38}$ Ley del Proceso Penal para el Estado de Guanajuato. "Artículo 161. Los medios alternativos de solución de controversias señalados en el artículo anterior relativos a la mediación y la conciliación, podrán aplicarse desde antes de que se presente la denuncia o querella, hasta antes de que se dicte el auto de apertura del juicio oral."

${ }^{39}$ Como consecuencia del diálogo, aparecen distintas soluciones, pero todas mantienen un objetivo común: recuperar la tranquilidad, y para ello, la petición de perdón, el reconocimiento de los hechos o de los errores cometidos, el abono de la indemnización y, en algunos casos, la retirada de la denuncia son las exigencias principales. Para mayor información véase RÍOS MARTÍN, Julián Carlos et al, Op. Cit., nota 29, p. 83.

${ }^{40}$ Mecanismo compensatorio que se empieza a extender en México y que es importante se siga haciendo viable en los sistemas comunitarios, judiciales y penitenciarios para eliminar o reducir barreras sistemáticas de carácter legal, incentivar su uso, crear mecanismos que provean dirección y estructura a sus programas, 
caso, no nos referimos a la oportunidad como criterio sino como a la oportunidad de acceso a los MASC con relación a los diversos momentos de un proceso penal, en que tanto víctima como victimario podrían tener la posibilidad de acceder a los MASC. ${ }^{41}$

Otra cuestión, que es importante precisar, es sobre la capacitación inicial, certificación y requisitos que deberán tener los especialistas de los MASC, como lo pueden ser, mediadores/conciliadores o llamados en su conjunto "Facilitadores", en caso de ser posible la ley nacional de MASC en materia penal, ${ }^{42}$ término que se define, en el glosario contenido en la fracción V, del artículo $3^{\circ}$, de la misma ley, como el profesional certificado, del Órgano cuya función, es facilitar la participación de los Intervinientes en los MASC en materia penal.

Por otro lado, en la misma ley nacional se requiere, que el Facilitador para ingresar al órgano, ${ }^{43}$ se debe encontrar debidamente capacitado y certificado, cumpliendo con 180 horas de capacitación teórico-práctica en los MASC y renovando su certificación cada 3 años con 100 horas de capacitación. ${ }^{44}$ Es importante este avance, que se podría ver reflejado en la actuación y capacidad de los facilitadores; con lo que se aduce, que los Mediadores, Conciliadores, Ministerios Públicos o Fiscales y Jueces, deben estar preparados, capacitados y certificados para atender una solicitud o derivación de la mejor manera; lo anterior, en pro de que no se confundan los términos que se emplean en el argot judicial o administrativo ni los principios que se persiguen en los MASC, como el de voluntariedad; por expresar algunas ventajas que se aportarían al exigírseles a todos los intervinientes una capacitación como a los especialistas, por que se hace preciso garantizar que la asesoría sea la adecuada, por ser en múltiples casos que se plantean, la primera información que podrían recibir tanto la víctima como acusado. Por lo que se aduce, que el Fiscal y Juez, desde que tengan cono-

asegurar la protección de los derechos de victimarios y víctimas que participen en programas restaurativos, así como, establecer principios, guías y mecanismos de monitoreo para adherirse a dichos principios. Para mayor información sobre recomendaciones respecto a la justicia restaurativa véase la Declaración de Costa Rica: sobre Justicia Restaurativa en América Latina, 2005. En: http://www.justiciarestaurativa.org/news/ crdeclaration/. Fecha de consulta 18 de marzo de 2014.

${ }^{41}$ Respecto a la oportunidad para acceder a los MASC el Artículo $6^{\circ}$ de la ley nacional dispone: “Oportunidad. Los Mecanismos Alternativos podrán ser aplicados desde el inicio del procedimiento penal y hasta antes de dictado el auto de apertura a juicio o hasta antes de que formulen las conclusiones, según corresponda, de conformidad con lo dispuesto en la legislación procedimental aplicable". Con lo que se elimina la posibilidad de acceder a los MASC antes de presentar denuncia o querella, en concordancia con el artículo 188 de la misma ley nacional de MASC.

${ }^{42}$ Certificación inicial, que según el artículo cuarto transitorio, de la Ley Nacional de MASC en materia penal, deberá concluir antes del 18 de junio de 2016 y que dentro del segundo párrafo del mismo artículo transitorio se dispone, que "dentro de los sesenta días siguientes a la publicación de este Decreto..., la Secretaría Técnica de la Conferencia Nacional de Procuración de Justicia, así como la Secretaría Técnica del Consejo de certificación en sede judicial deberán elaborar el proyecto de criterios mínimos de certificación de Facilitadores. Para la elaboración de los criterios referidos deberán tomar en consideración la opinión de los representantes de las zonas en que estén conformadas la Conferencia y el Consejo. El proyecto deberá ser sometido a consideración del Pleno de la Conferencia o el Consejo en la sesión plenaria siguiente al vencimiento del plazo a que se refiere este párrafo." Y se hace la precisión en el artículo 48, que dentro de los requisitos para ser un facilitador, serán: I. Poseer grado de Licenciatura afín a las labores que deberán desarrollar, con cédula profesional con registro federal; II. Acreditar la certificación que establece esta ley; III. Acreditar las evaluaciones de control de confianza que establecen las disposiciones aplicables para los miembros de instituciones de procuración de justicia; IV. No haber sido sentenciados por delito doloso, y V. Los demás requisitos que establezca esta Ley y otras disposiciones que resulten aplicables.

43 La fracción X, del artículo $3^{\circ}$ de la Ley Nacional de MASC en Materia Penal señala que el órgano es "la Institución especializada en Mecanismos Alternativos de Solución de Controversias en materia penal de la Federación o de las entidades federativas."

${ }^{44}$ Según lo dispone, el artículo 50 de la Ley Nacional de MASC aludida. 
cimientos de los hechos conflictivos, tendrán que dominar y poner en conocimiento de las personas las indulgencias y beneficios de asistir a los MASC, así como, valorar y transmitir sensiblemente a la sociedad los casos en que podrían ser utilizables o no los MASC, entre otras habilidades y destrezas.

Por lo tanto, un juez como un fiscal, se hace preciso que tengan una capacitación relativa, continua y de acuerdo a sus funciones, como la que se podrán exigir a los facilitadores, con lo que se pretenda dominar y explicar en su función las bondades de acudir a los MASC, así como, sus ventajas y desventajas, de manera general, para dar una introducción, centrándose en explicar en qué consisten, las posibilidades de dirimir la controversia planteada, basándose en el ordenamiento jurídico que regula sus principios, organización y funcionamiento; así mismo, se hace necesario un estudio y transmisión sobre las principales diferencias y similitudes entre seguir una justicia formal o una justicia alternativa; por lo que sus operadores (especialistas, juez y fiscal) deben dominar cuál es el alcance y contenido de los apartes normativos cuestionados con relación a la naturaleza de la controversia, con el fin de explicar y distinguir los delitos susceptibles a mediación o conciliación y la oportunidad de acceder a los mismos (fases) para concluir sobre su posible encause o derivación a la unidad receptora, mediador, conciliador o especialista; con lo que se ayude a disminuir la distancia entre el ser y el deber ser.

Por lo que se aduce, que con la implementación de salidas alternas en la solución de controversias jurídicas, se puede favorecer a la materialización de un desarrollo equilibrado y ponderado para la protección de derechos humanos con la dimensión que marca nuestra Constitución Federal y, que se precisa en las democracias modernas, con lo que se fomente una justicia y paz social, como a una mayor eficacia de las políticas dirigidas a la prevención del delito y sus posibles soluciones.

\section{PROPUESTA DE PROTOCOLO PARA LOS OPERADORES DE LOS MASC Y SU DERIVACIÓN}

Para contribuir a un mejor empleo y difusión de los MASC, como de la mediación y conciliación en el ámbito penal, se ha requerido no solo expansión de los Centros de Justicia Alternativa que atiendan la materia penal, como se ha venido haciendo en diversas entidades federativas de México o recursos para su presencia en todo el país y, así contribuir a su viabilidad, sino también, se ha hecho necesario la coordinación entre instituciones del país, como Procuradurías Generales de Justicia, Poderes Judiciales de los Estados y de la federación, Centros de Justicia Alternativa y Defensorías Públicas, donde se pueden incluir a defensores o mediadores privados, para que en su conjunto se contribuya a fortalecer integral y sistemáticamente la calidad en su posible intervención.

Por lo que se sigue haciendo necesario, la mejor comprensión y materialización de los MASC nacionalmente, la generación de instrumentos de sensibilización, actuación y socialización, como por ejemplo, con la inclusión de protocolos de actuación para la remisión y trasiego de asuntos susceptibles a utilizar MASC, con lo que se pueda contribuir a la eficacia y mejor desarrollo de las funciones de un operador $y$, donde no solamente, se podría limitar o aclarar su uso, sino también, su encause y derivación, teniendo como objetivo estratégico 
y general, garantizar una mejor experiencia a la ciudadanía como a las personas encargadas de la administración de justicia penal. ${ }^{45}$

Nos referimos brevemente, a una propuesta de protocolo de actuación para los operadores de los MASC en materia penal, que pudiera servir y seguir desarrollándose, en aras de una estandarización, así como, para contribuir a mejorar el uso y funcionamiento de los MASC al relacionarse con su aplicación y desarrollo, con lo que se podría coadyuvar a clarificar la actuación o función de los intervinientes en conflictos penales que pudieran ser susceptibles o derivados a mediación o conciliación, ${ }^{46}$ por lo que la propuesta tiene relación con la actuación que es deseable siga su operador en su encause y derivación, en beneficio de la sociedad, Estado y partes involucradas en una controversia, con lo que se busque fortalecer la extensión de la mediación o conciliación como expresión o fórmula de la Justicia Restaurativa.

Con esta propuesta de protocolo, se procura atender problemas sociales, como el mejoramiento en la forma de acceder, funcionar y entender el objetivo y oportunidad de los MASC en materia penal, en pro de contribuir a materializar un mejor derecho, una mejor administración de justicia, de manera gratuita e igualitaria, así mismo, a la adecuación estructural y normativa de los MASC y su estandarización ante una justicia restaurativa que se busca, sobre todo, para la realización de sus principios, por lo que se propone un protocolo para constituir un instrumento de consulta, capacitación y sub garantía de derechos humanos en un Estado Constitucional y, con lo que la reforma en materia penal en México al relacionar

\footnotetext{
${ }^{45}$ Por otro lado, señalan los mediadores que en la mayoría de los Centros de Mediación, ha sido necesaria la creación de un flujograma y el establecimiento de protocolos o procedimientos para el trabajo de los casos, los cuales, definen el recorrido que debe realizar una causa penal desde que es derivada a mediación y sus plazos. Estos protocolos describen el tratamiento de los casos en cuanto a las etapas y sus objetivos para el proceso de mediación penal. Una vez efectuada la derivación del caso, habitualmente se realiza una evaluación centrada en las condiciones psicológicas, jurídicas, expectativas y la voluntad de las personas para participar en la mediación, y se analiza el tipo de delito de que se trata. A este examen en el caso de las víctimas, se le llama examen de vulnerabilidad y, se usan para estos efectos, criterios técnicos. Para mayor información véase GONZÁLEZ RAMÍREZ, Isabel Ximena y FUENTEALBA MARTÍNEZ, María Soledad, "Mediación Penal como Mecanismo de Justicia Restaurativa en Chile", Revista Chilena de Derecho y Ciencia Política, Chile, Vol. 4, No. 3, septiembre-diciembre de 2013, pp. 175-210.

${ }^{46}$ Donde se incluye y se hace pertinente para los fiscales, mediadores, conciliadores, jueces y partes, sin una visión limitativa de sujeción a la propuesta de protocolo, sino con la perspectiva de proponer un mecanismo o modelo (flujograma) para la mejor interpretación, actuación y materialización de derechos humanos, con diversas formas de solución a los conflictos penales, con miras a resolver problemáticas y, que aunque podría no existir el mismo protocolo, se hace propicio para la mejor implementación de los MASC con relación a Jueces o Fiscales con costumbres arraigadas y seguidas en un sistema inquisitivo o mixto inquisitivo, si se le pude llamar sistema, al no incluir en la mayoría de los casos a la víctima.

Como en otros países se ha venido haciendo, desde el 2007 en la comunidad autónoma de Euskadi o País Vasco; por lo que en España, ha venido progresando desde Julio de 2008, que se elaboró un Protocolo de Mediación Penal, que regulaba pormenorizadamente el funcionamiento de los Servicios de Mediación Penal en sus relaciones con los órganos judiciales para la remisión y trasiego de asuntos, así como, la eficacia de las mediaciones entre otras cuestiones. Era una labor necesaria entonces, debido no solo a la falta de regulación legal específica de ámbito estatal sobre la materia de mediación, tanto en el Código Penal como en la Legislación Procesal, sino sobre todo, por tratarse de la primera vez que se iba a introducir una fórmula alternativa de resolución de conflictos, a la que se quiso dar, con acierto, la mayor concreción posible para garantizar el éxito de la experiencia. Para mayor información véase el Protocolo de Funcionamiento del Servicio de Mediación Intrajudicial. Procedimiento de Mediación Penal, Dirección de Justicia, Departamento de Justicia y Administración Pública. file://C:/Users/UABC/Downloads/PROTOCOLO\%20\%20DE\%20 MEDIACI\%C3\%93N\%2oPENAL\%2oINTRAJUDICIAL.pdf, fecha de consulta: 10 de julio de 2014.
} 
a los MASC como una oportunidad y posibilidad para resolver controversias penales, siga progresando en su consecución y mejor concreción.

Por lo que esta propuesta de protocolo, parte de entender mediación/conciliación penal como un medio o método para la intervención, en la posible solución de una controversia, por una tercera persona o equipo cualificado o aceptable, imparcial, neutro y capacitado que ayude a propiciar que las partes asuman de manera voluntaria participar en el proceso de mediación o conciliación ante un conflicto penal, a la vez, que permita a ese tercero, encausar sensiblemente sin ningún poder de decisión o ejecución $y$, que pretenda que las partes desarrollen sus acuerdos viables, satisfactorios y, capaces de responder a las necesidades de las mismas (en el caso penal, víctima y probable responsable, acusado o imputado) tratando con ello, solucionarlo de forma autocompositiva y minimizando la posibilidad de un litigio o sus consecuencias jurídicas estigmatizantes.

Entendiendo a la mediación o conciliación penal, como método que puede ayudar a un control social de comportamientos, tomando en cuenta que una de sus funciones más importantes, son la de servir de medios para una reparación del daño, esto, una vez generado el proceso de comunicación, en el caso de la mediación, en que la víctima y el infractor podrían llegar a un acuerdo asistido o en el caso de una conciliación donde la asistencia podría proponer soluciones viables; en ambos casos, se puede contribuir a la reparación de daños, material e inmaterialmente, y que en su caso, podrían afectar positivamente a una controversia penal planteada.

Cuando una vez analizada la controversia, se decida que el mejor tratamiento sería solucionarlo, a través, de los MASC judicial o administrativamente, se podría llevar a cabo una derivación del conflicto planteado a un especialista en MASC, sea desde antes de iniciar la investigación o una vez planteado el problema en sede judicial. Con lo que se hace necesario, que no solamente sean capacitados y certificados los mediadores o conciliadores en los MASC (como lo dispone, la ley nacional de MASC en materia penal), sino también, los fiscales y jueces, al poder introducir la redefinición de una controversia, que podría propiciar una forma diversa de solución que la seguida en un litigio. Por lo que la ley parte de atender como objetivo general, el cambio de paradigma respecto de un sistema penal inquisitivo mixto excluyente a un sistema acusatorio incluyente "humanista" 47 que puede contribuir a la posibilidad de los MASC para el restablecimiento de la paz social y jurídica. ${ }^{48}$

Dentro de los objetivos específicos de esta propuesta de protocolo, se encuentran: servir a la mejor comprensión, capacitación y garantía en la solución de conflictos, a través, de los MASC, como ser un instrumento de consulta, comprensión y sensibilización para las personas, donde se incluya íntimamente a los sujetos procesales, ajenos o no al conflicto y que

47 VIDAURRI, ARECHIGA, Manuel, Teoría General del Delito, Oxford, México, 2013, p. 240. Aduce, que se sostiene con justa razón que con la implantación del sistema acusatorio se sientan las bases de un proceso penal garantista, que vela por los derechos de las víctimas y que, igualmente, procura hacer más ágil y transparente la impartición de justicia, al propiciar un equilibrado interactuar de las partes intervinientes en el proceso.

${ }^{48}$ HERNÁNDEZ AGUIRRE, Christian Norberto et al, "Los métodos alternativos para la solución de conflictos penales en México", Memoria del congreso internacional de abogacía, ediciones ONBC, La Habana, Cuba, 2014. Aduce, en correlación con la paz que se busca a través de los MASC, que es, a través de ellos, donde precisamente intervienen los especialistas de la materia, como los negociadores, mediadores, conciliadores y árbitros, que interactúan entre lo humano y lo técnico... Por lo que al aplicar los MASC en la solución de controversias, no tan sólo es una gran responsabilidad, pues una vez que se interviene en la solución del conflicto, rara vez las cosas vuelven al estado en el que se encontraban (o nunca, ya que, se redefine como en un proceso judicial pero sin la resolución o ejecución en "manos" de un tercero). 
podrían tener intervención, desde su encause, solicitud, derivación y desarrollo. Así mismo, favorecer la humanización, ponderación y armonización racional y razonable al convivir entre reglas, valores y principios en la resolución de conflictos penales, colaborando en prácticas en pro de su mejor solución, atendiendo a los principios que enmarcan a los MASC, así como, a contribuir en una mejor solución democrática, participativa y proporcional, dejando o minimizando la intervención punitiva del Estado, con la nota característica de ser la ultima ratio ${ }^{49} \mathrm{y}$ dejando de ser un sistema que contribuya a un derecho penal simbólico.

El protocolo, modelo o guía de actuación que se propone, es para servir de orientación y capacitación continua para un operador de los MASC, tanto en la forma de actuar como en la forma de derivar un conflicto a mediación o conciliación, al mismo tiempo, que sea un instrumento informativo y que ayude a la transmisión sobre la consistencia de la mediación o conciliación, con lo que se contribuya a una mejor ponderación de la controversia y, que existan posibilidades de una solución alternativa a la que se da en un litigio.

Por lo que se pretende, que dentro del mismo protocolo se exprese una explicación pormenorizada de los principios de los MASC, los delitos y situaciones en que sea posible su procedencia u oportunidad (aunque sea repetitivo) sobre los momentos procesales en que pudiera ser posible su derivación y valoración, así como, los órganos encargados de su atención y derivación, distinguiendo, los que tendrán a cabo su posible derivación de los que los tratarán, así como, sus límites y como deberá desempeñarse y dirigirse un juzgador, un fiscal o un especialista, hasta la inclusión de formatos que se podrían utilizar en la práctica y, en los que se podría observar la diferencia entre una orden que pudiera emitir un fiscal o un juez (como por ejemplo, de comparecencia o de presentación, en que resulta obligatoria la comparecencia para las partes), y lo que es una invitación o derivación a los MASC (que resulta voluntaria), como también, la forma o propuesta de forma de los convenios o acuerdos sin ser exhaustiva o limitativa sino orientativa.

\footnotetext{
${ }^{49}$ VIDAURRI ARÉCHIGA, Manuel, Introducción al derecho penal, Oxford-Universidad de Guanajuato, México, 2012, p. 18. Aduce, que la nota característica del derecho penal de ultima ratio (último recurso) insiste en ese rol secundario o subsidiario...Por las graves y trascendentes consecuencias que conlleva la aplicación del derecho penal que tiene sentido al considerarlo como la última razón. Esto significa que en el paradigma del Estado social y democrático de derecho, el uso del derecho penal no es la prima ratio, sino la ultima. Por desgracia, la tendencia expansiva del derecho penal ha propiciado que en, más de una ocasión, esta poderosa herramienta de control social formal no sea ya la última, sino la prima ratio. Más crudo y peligroso será que llegue a ser la unica ratio.

Por otro lado, sobre la vertiente normativa del principio de proporcionalidad, en concordancia con GORDILLO SANTANA, Luis, op. cit., nota 10, p. 28. (o el principio de proporcionalidad en sentido estricto), exige que la mediación, en cuanto asunción voluntaria de la responsabilidad a partir de la conciliación con la víctima tenga lugar en unas condiciones que no resulten excesivas en relación al fin de protección preventiva de bienes jurídicos y pacificación social, que no implique unas cargas que no se justifiquen conforme a la consecución del mencionado fin. En este sentido, la cuestión de que se acepten prestaciones que exceden más allá de los exigible conforme a la gravedad del hecho, es una cuestión que preocupa y, en consecuencia, deben valorarse dos aspectos a la hora de interpretar el principio de proporcionalidad en este contexto. Por un lado, la existencia de una obligación civil que antes o después habrá de asumir el autor y, por otro lado, la espontaneidad- voluntariedad en la disposición de dialogar con la víctima, sea para excusarse, sea para ofrecerle otro tipo de prestaciones o apoyos. En el proceso de mediación se producirá la generación de un $<<$ tercer espacio $>$, donde ambas partes puedan negociar sus diferencias y sus intereses a través de un proceso participativo con cabida para el diálogo y la comprensión de los sentimientos del otro, que nos va a llevar, sin duda, a acuerdos que no siempre comprenderán reparaciones económicas sino más vinculadas con el "mundo interno".
} 


\section{CONCLUSIONES}

Primera. Los MASC en materia penal, son una opción viable para la despresurización del sistema de administración de justicia, teniendo en consideración las particularidades de cada organismo y personas que los traten, teniendo en cuenta sus competencias generales y específicas en las diversas temáticas de la controversia a intervenir, así mismo, con la utilización de diversas teorías y métodos, se puede contribuir a la maximización de derechos y libertades.

Segunda. Los MASC, si bien se proponen como medios o métodos para alcanzar la paz y justicia social, los mismos encuentran su dimensión en la Constitución Federal y, a través, de una regulación y aplicación efectiva y sensible a la sociedad, con lo que se pueda favorecer su uso; por lo que se aduce, que se deberán seguir perfeccionando en su instrumentación como para su garantía y, se propone entre ello, un protocolo de actuación que cuente con criterios claros, orientativos y uniformes para los centros de mediación, facilitadores, fiscales y jueces, respetando la particularidad cultural y social de cada región, con lo que se ayude a mejorar los niveles de eficiencia del sistema de administración de justicia, así como, a la satisfacción de usuarios, al contar con procedimientos estandarizados a niveles institucionales.

VII. FUENTES

BIBLIOGRÁFICAS

BARATTA, Alessandro, Criminología y Sistema Penal, México, B de F, 2004.

BARUCH BUSH R. A. Y FOLGER J. P., La promesa de mediación. Cómo afrontar el conflicto a través del fortalecimiento propio y el reconocimiento de los otros, Argentina, Granica, 1994.

DOMINGO DE LA FUENTE, Virginia, "Justicia Restaurativa y Mediación Penal de la teoría a la práctica." Revista de derecho penal, Lex Nova, No. 23, Madrid, 2008.

FIERRO FERRÁEZ, Ana Elena, Manejo de conflictos y mediación, México, Oxford, 2010.

GONZÁLEZ RAMÍREZ, Isabel Ximena y FUENTEALBA MARTÍNEZ, María Soledad, "Mediación Penal como Mecanismo de Justicia Restaurativa en Chile", Revista Chilena de Derecho y Ciencia Política, Chile, Vol. 4, No. 3, septiembre-diciembre de 2013 .

GORJÓN GÓMEZ, Francisco Javier y SÁENZ LÓPEZ, Karla Annet Cynthia, Métodos alternos de solución de Controversias. Enfoque educativo por competencias, México, Universidad Autónoma de Nuevo León-Editorial Grupo Patria, 2011.

conflictos, $2^{\mathrm{a}}$ ed., Oxford. México, 2012. petración de la justicia”, en ELIALA, año 2, núm. 3. UANL, México, 2002. 
GORDILLO SANTANA, Luis, "Los principios constitucionales y las garantías penales en el marco del proceso de mediación penal", Revista Redur, No. 4, Universidad de La Rioja, Departamento de Derecho, 2006.

HASSEMER, Winfried, Porque no debe suprimirse el Derecho Penal, México, D. F., INACIPE, 2003.

HERNÁNDEZ AGUIRRE, Christian Norberto et al, "Los métodos alternativos para la solución de conflictos penales en México", Memoria del congreso internacional de abogacía, ediciones ONBC, La Habana, Cuba, 2014.

HOBBES, Thomas, Leviatán: la forma y poder de un estado eclesiástico y civil, Madrid, Alianza, 2002.

Manual General para Operadores Jurídicos, Técnicas del Proceso Oral en el Sistema Penal Acusatorio Colombiano, $2^{\mathrm{a}}$ ed., Colombia.

Manual del mediador "Proyecto para la Mediación en México", ABA/USAID, 2004.

Cuadernos del Mercosur, "La mediación en Argentina y el Mercosur." número 12.

MÁRQUEZ ALGARA, Ma. Guadalupe, "Desarrollo de la mediación judicial en México", Jurisconsulto, Aguascalientes, año 1, No. 1, México, Julio-Diciembre de 2005.

- y DE VILLA CORTÉS, José Carlos, “La justicia restaurativa y la mediación penal en México”, revista De Jure, Universidad de Colima, México, año 3, No. 8, Mayo 2011.

OVALLE FAVELA, José, Teoría General del Proceso, 10ª ed., Oxford, México, 2011.

PÉREZ SAUCEDA, José Benito y ZARAGOZA HUERTA, José, en CAMPOS DOMÍNGUEZ, Fernando G., CIENFUEGOS SALGADO, David, RODRÍGUEZ LOZANO, Luis G., ZARAGOZA HUERTA, José (coords.), "Justicia Restaurativa: del castigo a la reparación”, en Entre libertad y castigo: dilemas del estado contemporáneo. Estudios en homenaje a la maestra Emma Mendoza Bremauntz, Editora Laguna, México, 2011.

PRADO MAILLARD, José Luis y GORJÓN GÓMEZ, Francisco Javier (coord.), Modernización de la justicia desde la perspectiva panameña y mexicana, Panamá, Carpal, 2013.

PRIETO SANCHÍS, Luis, Justicia Constitucional y Derechos Fundamentales, $2^{\mathrm{a}}$ ed., trad. Carlos Bernal Pulido, Madrid, Trotta, 2009. cionalidad y la interpretación constitucional, V\&M Gráficas, Ecuador, 2008.

REDORTA, Josep, Como analizar los conflictos. La tipología de conflictos como he r r a mienta de mediación, Buenos Aires, Paidós, 2004.

SCHNITMAN Dora Fried (Comp.), Nuevos paradigmas en la resolución de conflictos. Perspectivas y prácticas, Buenos Aires, Granica, 2000.

SUPREMA CORTE DE JUSTICIA DE LA NACIÓN, El sistema penal acusatorio en México: estudios sobre su implementación en el poder judicial de la federación, México, 
Dirección General de la Coordinación de Compilación y Sistematización de Tesis, 2008.

VIDAURRI ARÉCHIGA, Manuel, Introducción al derecho penal, Oxford-Universidad de Guanajuato, México, 2012.

_- - _ — _ - Teoría General del Delito, Oxford, México, 2013.

INTERNET

Ley Nacional de Mecanismos de Mecanismos Alternativos de Solución de Controversias en Materia Penal.http://www.dof.gob.mx/nota_detalle.php?codigo=5377563\&fecha=

29/12/2014. Fecha de consulta: 06 de enero de 2015.

Declaración de Costa Rica: sobre Justicia Restaurativa en América Latina, 2005. En: http:// www.justiciarestaurativa.org/news/crdeclaration/. Fecha de consulta 18 de marzo de 2014 .

Manual sobre programas de Justicia restaurativa, Oficina de las Naciones Unidas contra la droga y el delito, Nueva York, 2006. http://www.unodc.org/documents/justice-andprisonreform/Manual_sobre_Programas_de_justicia_restaurativa.pdf. Fecha de consulta: 05 de marzo de 2013.

Protocolo de Funcionamiento del Servicio de Mediación Intrajudicial. Procedimiento de Mediación Penal, Dirección de Justicia, Departamento de Justicia y Administración Pública, en File://C:/Users/UABC/Downloads/PROTOCOLO\%20\%20DE\%2o MEDIACI\%C3\%93N\%2oPENAL\%2oINTRAJUDICIAL.pdf. Fecha de consulta: 10 de julio de 2014.

RÍOS MARTÍN, Julián Carlos et al, Justicia restaurativa y mediación penal. Análisis de una experiencia (2005-2008), Consejo General del Poder Judicial, 2008. www.poderjudicial.es. Fecha de consulta 21 de junio de 2014.

Senado de la República, LXII legislatura, Diario de Debates, 03 de Septiembre de 2014, http:// www.senado.gob. $m x /$ index.php?ver $=$ sp\& $m n=3 \& s m=2 \& l g=62 \& a n o=1 \nLeftarrow i d=45049$. Fecha de consulta: 21 de septiembre de 2014 .

Corte Constitucional de Colombia, Sentencia C-893/o1 http://www.corteconstitucional.gov. co/relatoria/2001/C-893-01.htm\#_ftn12. 12 de Mayo de 2014.

\section{NORMATIVIDAD}

Constitución Política de los Estados Unidos Mexicanos. Actualizada a o7 de julio de 2014.

Código Nacional de Procedimientos Penal. Actualizado a 05 de marzo de 2014.

Código de Procedimientos Penales para el Estado de Baja California. Actualizado a 28 de septiembre de 2012 . 
Ley de Justicia Penal Restaurativa del estado de Durango. Actualizada a 03 de mayo de 2014.

Ley de Justicia Penal Alternativa del estado de Querétaro. Actualizada a 31 de marzo de 2014.

Ley de Mecanismos Alternativos de Solución de Controversias para el Estado de Sonora. Actualizada a 28 de febrero de 2013.

Ley de Mecanismos Alternativos de Solución de Controversias en el Estado de Yucatán. Actualizada a 24 de julio de 2009.

Ley del Proceso Penal para el estado de Guanajuato. Actualizada a 12 de agosto de 2011.

Ley de Justicia Alternativa del estado de Guanajuato. Actualizada a 21 de junio de 2011.

Ley de Justicia Alternativa para el estado de Baja California. Actualizada a 05 de abril de 2013. 